\title{
К ВОПРОСУ КАДРОВОГО НЕКОМПЛЕКТА ТЕРРИТОРИАЛЬНЫХ ПОДРАЗДЕЛЕНИЙ МВД РОССИИ
}

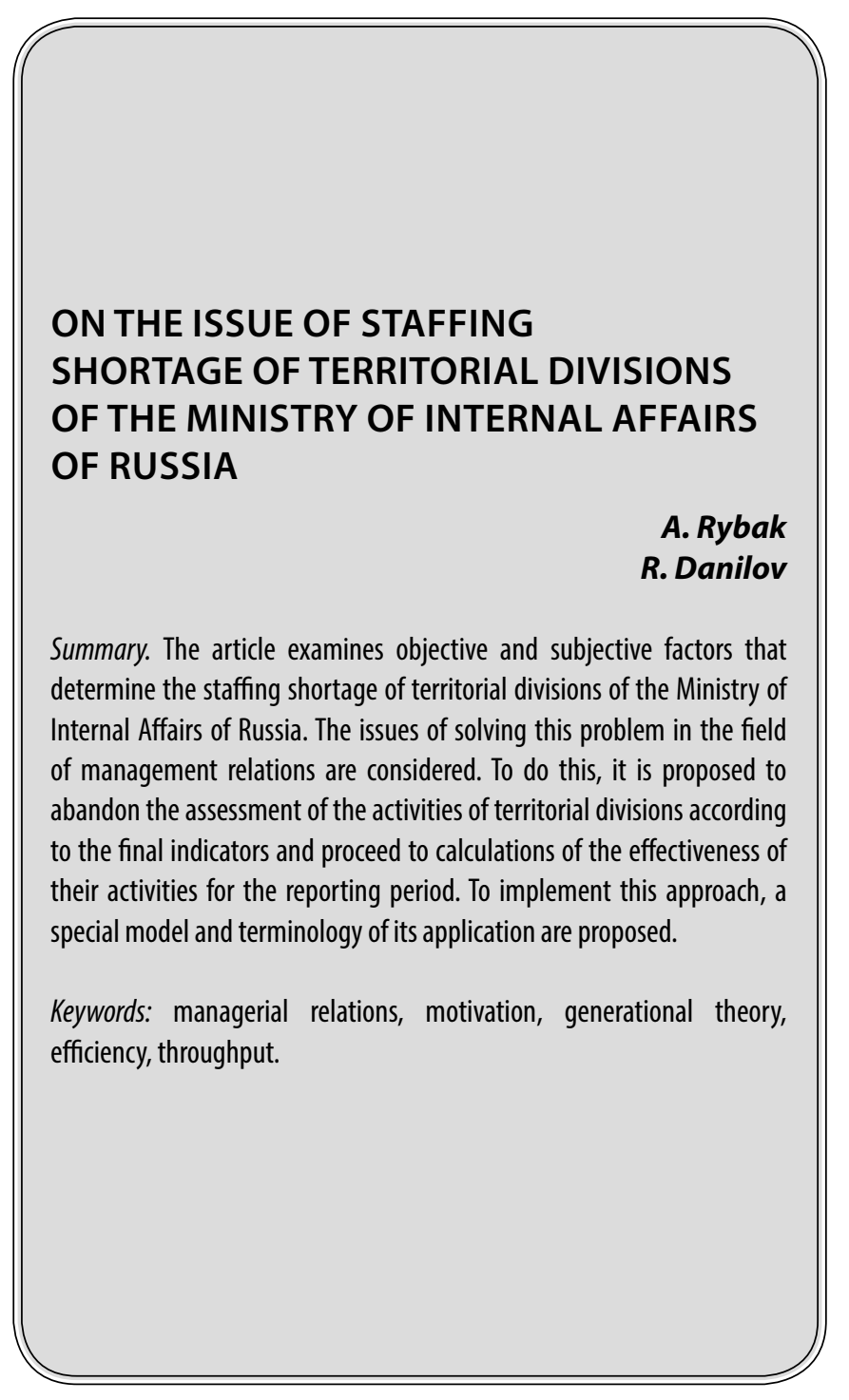

A ктивное внедрение современных информационных технологий во все сферы социально-политической и экономической жизни российского общества привело к значительным изменениям ее количественных и качественных характеристик в том числе и в области борьбы с преступностью. Длительный десятилетний тренд уменьшения количества зарегистрированных преступлений завершился. В 2019 г.- 2020 г. наблюдается стабильный рост по этому параметру. Хотя темп роста не значителен и находится в пределах статистической погрешности, удельный вес отдельных элементов структуры преступности претерпел существенную трансформацию.
Рыбак Александр Владимирович

К.т.н., доцент, Дальневосточный юридический институт МВД России

rybak_2908@mail.ru

Данилов Роман Михайлович

К.т.н., дочент, Дальневосточный юридический институт МВД России danilovroman@mail.ru

Аннотация. В статье исследуются объективные и субъективные факторы, определяющие кадровый некомплект территориальных подразделений МВД России. Рассматриваются вопросы решения этой проблематики в области управленческих отношений. Для этого предлагается отказаться от оценки деятельности территориальных подразделений по итоговым показателям и перейти к расчетам эффективности их деятельности за отчетный период. Для реализации этого подхода предлагается специальная модель и ехнология ее применения.

Ключевые слова: управленческие отношения, мотивация, теория поколений, эффективность, пропускная способность.

Прежде всего обращает на себя внимание рост тяжких преступлений и резкий, практически, взрывной рост сложных преступлений, совершенных с использованием информационно-телекоммуникационных технологий или в сфере компьютерной информации. Следует отметить, что до 2017 года эта категория преступлений вообще не выделялась в отчете МВД России «О состоянии преступности в России» и учитывалась в графе «мошенничество ст. ст. 159-159.6 УК РФ». Но ежегодное увеличение этих видов преступления с 1917 г. в 1.7-1.9 раза потребовало переключения фокуса внимания управленческих структур МВД России на эту категорию преступлений. 
Данная тенденция приобретает особенный характер в условиях пандемии, когда повсеместно внедряются новые информационные технологии, развивается цифровая грамотность; организационные, предпринимательские, образовательные и др. процессы интегрируются в он-лайн режим. Преступники умело встраиваются в новые реалии, активно используют вирусные и «зеркальные» сайты; создают идентичные государственные платформы, предлагая на них различные онлайн услуги, в том числе нелегальные.

Все это привело к тому, что в общей структуре преступности доля преступлений, совершенных с использованием информационно-телекоммуникационных технологий только в 2020 г. увеличилась по сравнению с 2019 г. почти в два раза, и составила $25 \%$. При этом раскрываемость этих преступлений уменьшилась до $18.6 \%$ (22.2\% в 2019 г.).

Учитывая реалии ухудшения экономической обстановки в стране и за рубежом, связанные с противоэпидемическими мерами, применяемыми государственными органами для защиты населения от коронавирусной инфекции (остановка деятельности предприятий, изоляция населения, удаленный режим работы и пр.), позитивных изменений в отмеченном тренде в ближайшие годы ожидать не следует.

То есть система органов внутренних дел как система управления перестала отвечать одному из основных кибернетических требований для поддержания своей жизнедеятельности и нормального функционирования -динамичности. Динамичность системы управления заключается в том, что органы внутренних дел должны оперативно реагировать на изменение внешней среды (экономической обстановки, состояния преступности) и дезорганизующие воздействия внутри системы, такие как некомплект личного состава, неудовлетворительное состояние служебной дисциплины, недостатки в управлении, низкий уровень квалификации сотрудников.

Таким образом вызовы современного общества требуют существенной перестройки деятельности правоохранительных органов. Большая доля ответственности в решении этой задачи лежим в области управленческих отношений. Следствием наличия в этой области множества нерешенных вопросов является сложившийся за последние пять - семь лет тренд кадрового некомплекта по основным подразделениям деятельности территориальных подразделений: предварительного следствия, дознания, уголовного розыска, участковых уполномоченных. Только по официальной статистике некомплект обозначенных подразделений доходит до $25 \%$, а с учетом больничных листов и того больше.
Остановимся на наиболее весомых причинах сложившейся ситуации.

Прежде всего обращает на себя внимание низкая мотивация большинства сотрудников территориальных подразделений на добросовестный труд и на повышение своего профессионального мастерства и личностного развития. Анализ нормативных документов, регламентирующих управленческие процессы в органах внутренних дел, а также большая практика проведения учебных занятий по профессиональной переподготовке руководителей территориальных органов МВД России на районном уровне, а также сотрудников, включенных в кадровый резерв, позволила выявить основные факторы, способствующие этому. Их следует разделить на два типа: объективные и субъективные.

В качестве объективных факторов следует обозначить прежде всего глобальные перемены, которые претерпело современное общество в связи с активным проникновением инфокоммуникационных технологий практически во все области человеческой деятельности.

Безграничные возможности интернета в сфере доступа к мировым информационным ресурсам привели к тому, что современный человек в большинстве своем во многом трансформировал свои жизненные ценности и соответственно интересы к новым реалиям. При этом следует обратить внимание, что наряду с профессиональными, гендерными, национальными и пр. интересами, объединяющих людей в социальные группы, каждый человек имеет «поколенческий» интерес, на основе которого формируется его способ мышления, а значит технология принятия решения, его поведенческие характеристики. Именно этот интерес подвергся кардинальным изменениям под воздействием так называемого «информационного взрыва».

Вопросы поколенческого интереса достаточно хорошо изучены и результаты опубликованы в 1991 г. американцами Нейлом Хоувом и Вильямом Штрауссом. Они проделали колоссальную работу по изучению повторяющихся «поколенческих» циклов в истории США вплоть до 17 века. В итоге была сформирована теория о циклической смене поколений с повторяющимися ценностями и настроениями. Согласно этой теории механизмом, который создает ценности поколения, его основные интересы, является процесс воздействия главных факторов и событий внешней среды, в которой первые двадцать лет жизни формируется личность человека. Люди одного поколения в большинстве своем имеют одинаковые ценности и интересы, схожие поведенческие характеристики [2]. 
Можно спорить о научности этой теории, но практический интерес к ней в мире нарастает, особенно в области социального управления.

Согласно ее основным канонам, полный цикл поколений состоит из четырех сменяющих друг друга архетипов. С точки зрения кадрового ресурса деятельности органов внутренних дел представляет интерес поколение Y (1983-2003 г.р.) и поколение Z (2003-2023 г.р.).

Поколение Y, более известное как «поколение миллениумов» сформировалось в условиях окончания «холодной войны», распада СССР, передела мира, появления интернета. Это дало миллениумам ощущение, что нет ничего идеального и вечного. Исходя из этого «миллениумы» не признают какие-либо идеалы, не уважают власть и авторитеты. Это первое поколение, глубоко вовлеченное в цифровые технологии. Интернет-пространство, давшее этому поколению большое количество возможностей для самовыражения, привело к тому, что каждый миллениум начинает чувствовать себя неповторимым и уникальным, не желает довольствоваться малым, считает, что достоин большего.

Хотя ценностями этого поколения являются гражданский долг, мораль и ответственность, им не интересен «длинный» труд с последующем вознаграждением в будущем. Идеалом является возможность быстро и без усилий достичь успеха и денежного благополучия.

«При этом, «миллениумов» отличает готовность к изменениям, возможность выбора, глобальная информированность, техническая грамотность, индивидуализм, стремление учиться в течение всей жизни, неформальность взглядов, поиск простых решений, прагматизм, надежда только на себя»

Представителей поколения Z отличает от миллениумов, то, что они «родились со смартфоном в руках». В отличии от поколения Y цифровые технологии окружают их с самого детства, а интернет является неотъемлемой частью жизни их родителей.

Они технически грамотны, привыкли к доступности любой информации. Ежедневно они путешествуют по миру при помощи интернета, наблюдая разнообразие мира, идеологий, культур и считают, что границы между государствам являются пережитком прошлого. Они уверены в себе и надеются, что окружающий мир: бренды, коллеги, подписчики - помогут им добиться целей, например, открыть свой бизнес [2].

Таким образом, трудно представить, что объективно сложившиеся ценности поколений Y и Z могут быть соизмеримы с ценностями службы в органах внутрен- них дел, где средний уровень заработной платы приблизился к уровню в гражданском секторе, а далекая перспектива раннего выхода на достаточно высокооплачиваемую пенсию соперничает с реалиями ненормированного рабочего времени, ограничением некоторых прав и свобод гражданина, сложными и запутанными индексами оценки деятельности сотрудника органов внутренних дел.

Сложившаяся ситуация требует новых подходов к организации правоохранительной деятельности, совершенствования кадрового обеспечения, поиска и разработки новых мотивационных механизмов способствующих повышению интереса поколений $\mathrm{Y}$ и Z к сфере деятельности органов внутренних дел среди гражданского населения и профессионального мастерства и добросовестного отношения к служебным обязанностям сотрудников территориальных подразделений МВД России.

Рассмотрим основные, наиболее проблемные вопросы управления деятельностью органов внутренних дел, которые являются субъективными факторами, определяющими сложившийся кадровый некомплект.

1. Решение вопросов материального обеспечения в настоящее время по прежнему стоит достаточно остро, в частности связанное с обеспечением проживания сотрудников в служебных квартирах или с наймом жилых помещений: способ решения этой проблемы в виде выплаты единовременной субсидии на протяжении последних лет мало способствует этому, в связи с незначительным количеством выделяемых средств.

Денежное довольствие сотрудников особенно в низовом звене фактически сравнялось с возможностями в гражданском секторе, а учитывая ряд ограничений, накладываемых на них в связи с прохождением службы, не является интересным для привлечения молодежи и специалистов гражданского сектора на службу в органы внутренних дел.

Повышенные служебные нагрузки, ненормированный рабочий день, эмоциональные перенапряжения и ряд других особенностей службы перестали соответствовать уровню материального обеспечения, позволяющему их компенсировать.

2. Личная ответственность руководителей за действия своих подчиненных даже в неслужебное время, доминирующий авторитарный стиль управления, не терпящий других способов решения задач кроме того, который указывает руководитель, также способствует понижению мотивации сотрудников, особенно в оперативных подразделениях, где поиск возможных способов 
решения задач, инициативность, наступательность, желание добиться результата всегда были залогом успеха в работе.

Желание руководителя добиться необходимого результата любой ценой, не принимая в расчет сложившуюся оперативную обстановку, достаточность кадровых ресурсов для решения служебных задач, состояние личного состава, его возможности - часто приводит к управленческому коллапсу. В этих условиях у части сотрудников формируется особое отношение к работе, которое заключается в стремлении получения второстепенных задач, никак не способствующих выполнению основной задачи по выявлению и раскрытию квалифицированных преступлений, в нежелании работать самостоятельно и добиваться результатов, приспособленческому поведению за счет других сотрудников. Все это вкупе с чрезмерной бюрократизацией работы, дополнительным привлечением к выполнению несвойственных подразделению функций создает серьезную дополнительную нагрузку на основной костяк сотрудников подразделений и формирует в нем нездоровый психологический климат.

3. Важным элементом, определяющим мотивацию сотрудников территориальных подразделений на результативный труд, а значит влияющим на сложившийся их некомплект является сложная, непрозрачная, достаточно противоречивая система оценки их деятельности.

Логика оценочного механизма заложена в приказе № 1040 «Вопросы оценки деятельности территориальных органов Министерства внутренних дел Российской Федерации» от 31.12.2013 г. В нем сделана попытка уйти от всеми критикуемой «палочной» системы оценки, когда результаты деятельности территориального подразделения оцениваются по статистическим показателям (количество уголовных дел, направленных в суд, количество административных протоколов и т.п.) и перейти к расчету итогов деятельности в баллах, рассчитанных по достаточно сложному индексу. К сожалению, в основе применяемой индексной оценки лежит принцип сравнения статистического показателя подразделения со средней величиной по региону, хотя и в опосредованной форме.

\section{Здесь имеют место ряд проблем.}

Первая - итоговый статистический показатель не всегда отражает количество труда, которое затратило подразделений для решения служебных задач. Оно безусловно зависит от профессиональной компетенции сотрудников, от уровня организации их деятельности. Но не в меньшей степени на результаты их труда влияет величина предельной нагрузки на одного сотрудника, сложность преступлений, зарегистрированных на курируемой территории, протяженность и рельеф местности, менталитет населения и пр. С учетом этого, оценка труда подразделений по статистическим показателям и последующему сравнению их между собой приводит к нарушению основных принципов управления, а в особо сложных ситуациях - к управленческому коллапсу.

Действительно, при превышении предельного уровня нагрузки на подразделение падает раскрываемость преступлений - розыскные мероприятия ослабляются, уголовные дела приостанавливаются, а следственная работа по ним, по сути, прекращается и т.д. Как следствие, повышается уровень латентной преступности, увеличивается количество слабо обоснованных отказных материалов, случаев укрывательства и нарушения учетно-регистрационной дисциплины.

Сложность преступлений, зарегистрированных на территории подразделения, влияет прежде всего на трудоемкость их раскрытия и расследования, часто требует специальных знаний и сложных экспертиз, большего времени расследования, что слабо отражается в итоговом статистическом показателе.

География местности часто оказывает самое непосредственное воздействие на результаты работы подразделения. Протяженность территории, рельеф местности, наличие дорог с качественным покрытием, отсутствие достаточного количества транспортных ресурсов все это оказывает прямое влияние на результаты работы.

Это далек не полный перечень всех аспектов деятельности территориальных подразделений по борьбе с преступностью, которые не охвачены официальной статистикой и не анализируются для объективной оценки их деятельности. На этом основании возникает потребность отказаться от алгоритма оценки деятельности подразделений на основе сравнения их между собой по индексу, изложенному в приказе № 1040 «Вопросы оценки деятельности территориальных органов Министерства внутренних дел Российской Федерации» от 31.12.2013 г. и перейти к оценке эффективности деятельности подразделений с учетом отмеченных выше факторов: профессиональной компетенции, уровня управления, сложившейся в отчетном периоде нагрузки, трудоемкости расследования зарегистрированных преступлений, географических особенностей территории, курируемой подразделением.

Для этого необходимо ввести в процедуру оценки норматив, который будет зависеть только от вышеперечисленных факторов и не зависеть от результатов работы других подразделений, как это имеет место 
в действующей технологии. Этот норматив можно назвать «пропускной способностью» одного сотрудника подразделения в условиях сложившейся криминогенной обстановки в отчетном периоде. Такой норматив должен актуализироваться каждый отчетный период и включать в себя необходимый уровень профессиональной компетенции, управления, среднюю трудоемкость преступлений, сложность расследования, связанную с особенностями местности и менталитетом населения.

Разработка модели расчета такого норматива требует проведения специальной экспертизы с участием ученых, руководителей подразделений, специалистов по направлениям деятельности.

Например, для следственного подразделения задачей экспертизы является классификация типовых преступлений на обозначенной территории на категории по величине трудоемкости их расследования. В ходе проведенной экспертизы должно быть определено количество категорий и выработаны типовые критерии, на основе которых в дальнейшем каждое преступление, будет отнесено в соответствующую своей трудоемкости категорию. Для каждой категории определяется ориентировочное время расследование преступлений, которое зависит от сложности преступлений, суммарного количества обоснованных следственных действий, сложности самих следственных действий, сложности экспертиз и пр. Отсюда выводится ориентировочное число преступлений данной категории, которое может расследовать один следователь за отчетный период, обладающий при этом необходимой квалификацией и профессиональными качествами с учетом особенностей оперативной обстановки данной территории.

Допустим, в результате проведенной экспертизы сформирована классификационная модель, состоящая из $k$ категорий трудоемкости расследования преступлений. Для каждой категории определена потенциальная возможность (ориентировочная норма) расследования преступлений за отчетный период для одного следователя в количестве: $n_{1}, n_{2}, n_{3} \ldots n_{k}$ уголовных дел.

Исходя из разработанной классификационной модели и данных статистики о преступлениях, находившихся в производстве подразделения, определяется доля преступлений каждой категории в общем количестве преступлений за отчетный период соответственно: $d_{l}$, $d_{2}, d_{3} \ldots d_{k}$

Тогда пропускную способность (назовем ее $\mathrm{Y}$ можно рассчитать по формуле средневзвешенной величины:

$$
\mathrm{Y}=\frac{\sum_{i=1}^{\mathrm{k}} d_{i} \cdot n_{i}}{\sum_{i=1}^{\mathrm{k}} d_{i}}
$$

Отсюда потенциальная «пропускная способность» $\mathrm{Y}$ представляет собой своеобразную норму количества труда, которое должен затратить следователь, обладающий необходимой квалификацией на расследование преступлений с учетом их разной трудоемкости за отчетный период.

Умножив рассчитанную «пропускная способность» Ү на количество следователей и разделив полученный результат на количество уголовных дел в производстве подразделения за отчетный период, мы получаем так называемый порог эффективности (2), позволяющий нам оценить результаты деятельности подразделения. Если итоговый результат (статистический показатель) работы подразделения близок или выше порога его эффективности, то оно заслуживает положительной оценки, если ниже - отрицательной. Величина разброса статистических показателей в процентах вокруг своего порога эффективности может служить основой для рейтинга подразделений.

$$
\alpha=\frac{Y \cdot R}{V},
$$

Такой подход позволит повысить мотивацию сотрудников и руководителей подразделений на результативный труд, так как оценка их работы будет определяться только количеством вложенного ими квалифицированного труда и не зависеть от результатов работы сотрудников соседних подразделений и динамики оперативной обстановки.

Действительно, при росте преступлений $V$ в производстве, согласно модели (2) соответственно уменьшается норматив эффективности $\alpha$, что позволяет подразделению при должной организации и достаточном количестве затраченного профессионального труда сохранить свой реальный уровень эффективности или даже его увеличить. В случае, роста в производстве сегмента сложных трудоемких преступлений уменьшается «пропускная способность» $Y$, что также ведет к уменьшению норматива эффективности $\alpha$ и реальной возможности подразделению сохранить свой статус-кво.

Таким образом, рассмотренные объективные и субъективные причины устойчивого кадрового некомплекта территориальных подразделений МВД РФ требует соответствующих решений в области кадровой политики, кадровой работы, в области совершенствования информационно-аналитической деятельности органов внутренних дел. 


\section{ЛИТЕРАТУРА}

1. Минаев В.А. Кадровые ресурсы органов внутренних дел: современные подходы к управлению. Монография. — М.: Академия МВД СССР, 1991.

2. Ожиганова Е.М. Теория поколений Н. Хоува и В. Штрауса. Возможности практического применения // Бизнес-образование в экономике знаний. Иркутск. 2015. № 1.

3. Попова 0.А. Оценка эффективности деятельности правоохранительных органов и качество расследования преступлений // Современные проблемы науки и образования. 2015. № 1. С. 1.

4. Рыбак А.В. Новый подход в оценке эффективности деятельности территориальных подразделений МВД России (на примере следственных подразделений) / А.В. Рыбак, К.М. Бондарь // Вестник Воронежского института МВД России. — 2018. № 4.

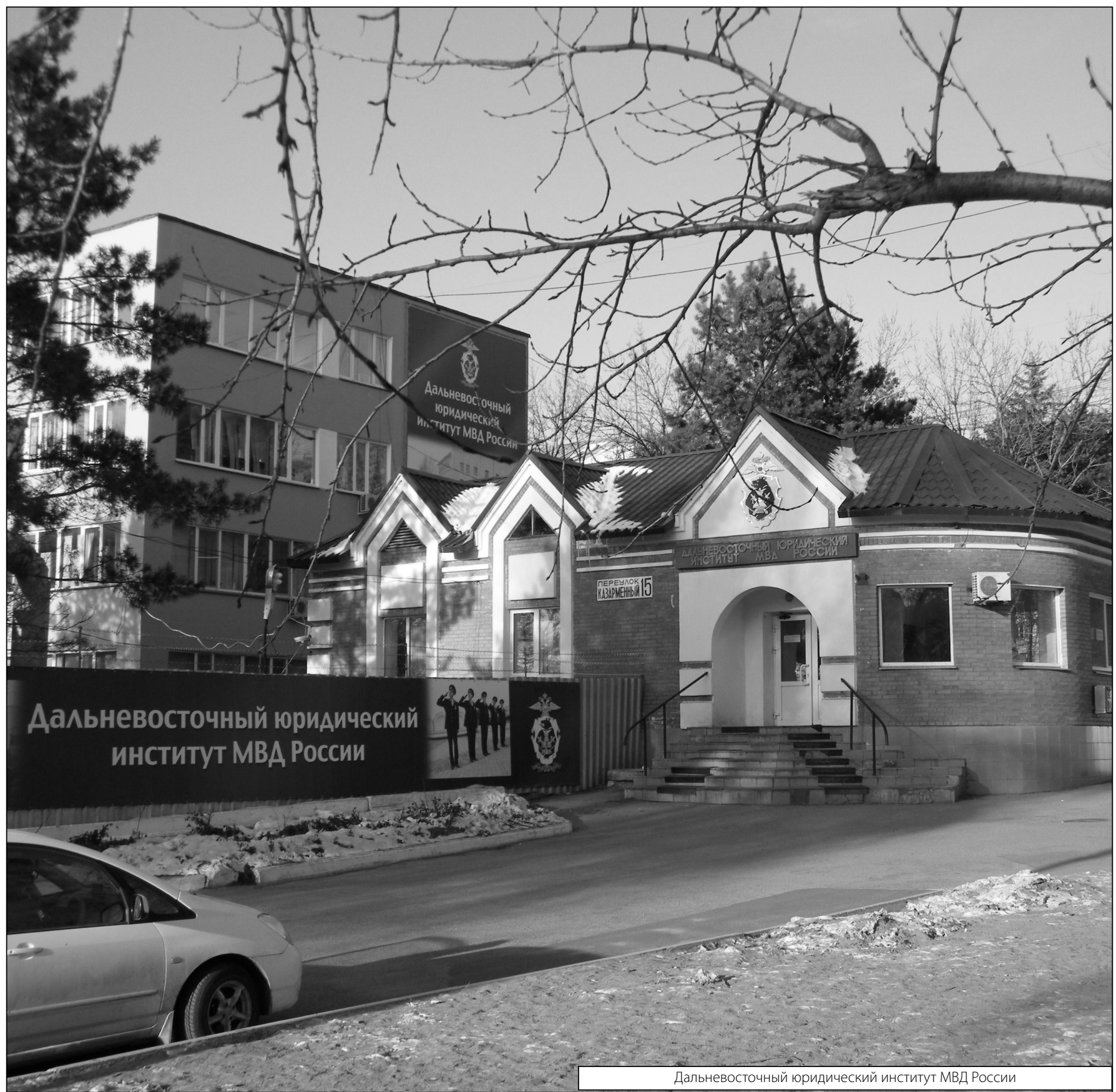

